\title{
Feasibility Study on the Promotion and Application of Straw Bale House in Northern Rural Areas in China
}

\author{
Xiaoming $\mathrm{Li}^{\mathrm{a}}$ \\ Shandong Urban Construction Vocational College, Jinan, China
}

\begin{abstract}
With the accelerated pace of new rural areas construction in northern China, people have a higher requirements in terms of houses' quality and function. At the same time, the backward construction methods and developing with the wind blindly has also led to a rapid growth in resource consumption. In order to better meet the requirements of hot comfort, energy saving and environmental protection properties of rural houses in northern areas. Based on the research methods including investigation, mathematical statistics, documentation, and logical analysis, combining with the residential problems in northern rural areas, and the superiority of straw bale house, and the favorable conditions for straw bale buildings. This article identified the feasibility of straw bale housing construction in the northern countryside, and draw the conclusion that the excellent economy, simple construction methods and good energy efficiency of straw bale house will be accepted by the majority of farmers friend.
\end{abstract}

\section{Introduction}

The pace of studying on ecological building materials is faster and faster. Although the new environmental protection materials are energy saving and good quality, it can also not be accepted by the people in northern rural areas of China. Because their backward construction methods and poor economic conditions. Comparatively speaking, straw materials are easy to obtained in rural areas. And people have no need to spend very great investment and a lot of effort on the study of straw baling technology. Furthermore, it is an urgent need to promote the innovation of wall materials and protect arable land. It is obvious that recycling straw resources is an feasible way to protect the environment and reduce the atmospheric fog and haze. So the straw bale houses have be widely constructed in Europe and America countrysides (Fig. 1). It has been fully proved that straw bale have superior performance as a kind of building material [1]. Today, innovation of better wall materials and promotion of energy-efficient buildings is an urgent need for arable land protecting and energy conservation. Recycling straw resources is an important way to protect the environment and reduce air pollution. And the straw bale building can meet these needs perfectly. For a Inadequate resources China, it is a important initiative to improve the energy efficiency of rural houses, who are $75 \%$ of the nationwide building area [2].

The date of investigation on part of the northern rural areas (Some research data is shown in Fig. 2) indicate that there have no housing insulation measures in $57 \%$ of the northern rural areas. Some of adobe houses and stone houses have able to meet the families' insulation requirement. But most of brick houses and concrete block houses are unsatisfactory [3]. Northern summer temperatures are not too high. But the winter are usually long and cold. Coal always be used as the primary fuel for heating and cooking. According to the statistics, wall area accounted for the largest proportion in building envelope.Through the wall, there will loss about $20 \%$ of the total heat capacity of the building in winter. And there will absorbed about $35 \%$ of the total absorption in summer. The heat loss of door and window accounted for $30 \%$ in the total building energy consumption. So it is important to design for the energy-saving of exterior walls, windows and doors. But which is always be overlook by residential construction in countryside. According to statistics, the coal consumption of a $100 \mathrm{~m}^{2}$ house in winter is about is 5 tons. Over the past five years, the price of coal has risen from 200 yuan to 500 yuan per ton. While the average annual income of northern farmers is only 2,500 yuan or less. So the fired spend occupies a large part compared with other household income [2]. In addition, the energy consumption for the adobe Kang heating can not be underestimated in most of the regions. In conclusion, for a house without enough insulation measures, room rate may not be much. But the residents have to pay for the subsequent energy consumption.

${ }^{\mathrm{a}}$ Corresponding author: xiaomingqwe@163.com 

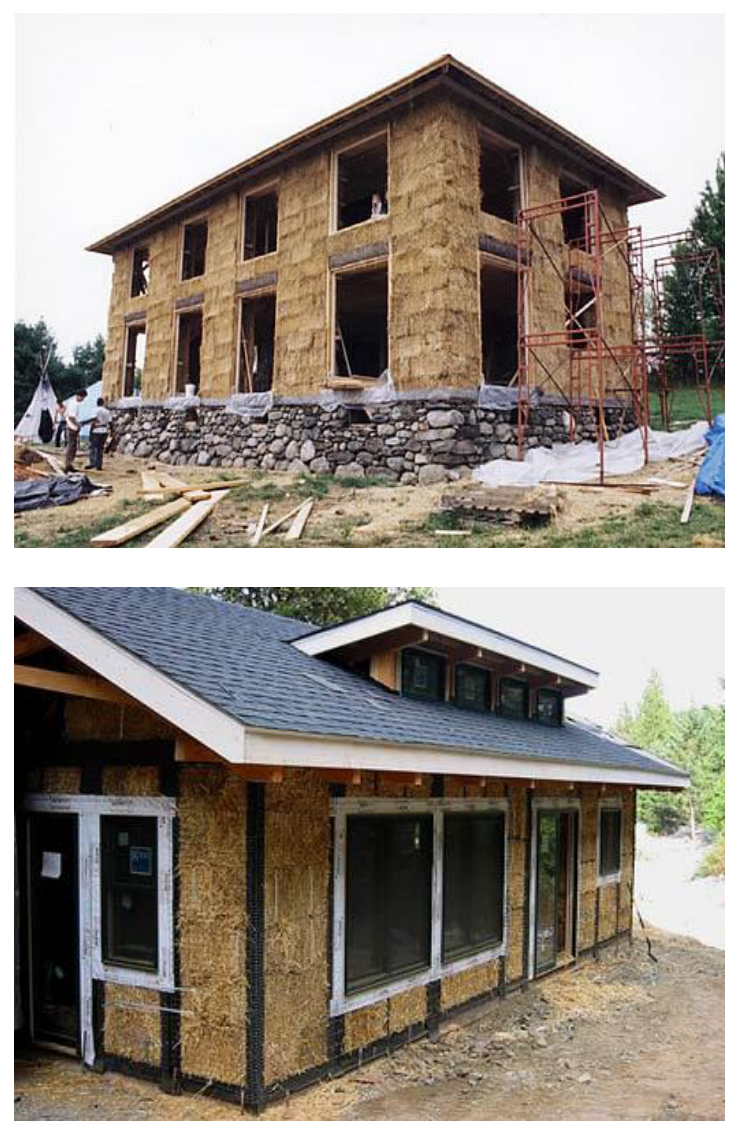

Figure 1. Large numbers of straw bale buildings are constructed in foreign countries.

\section{The Problems of Houses in Northern Rural Areas}

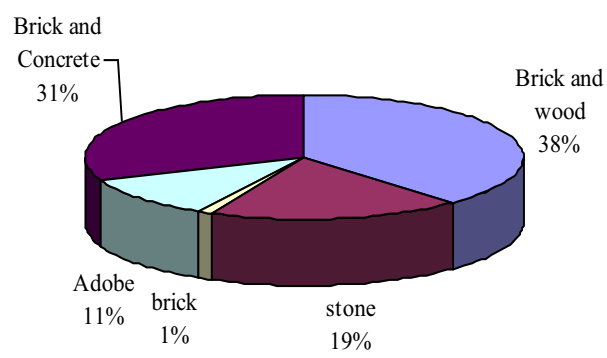

The main structure of existing homes

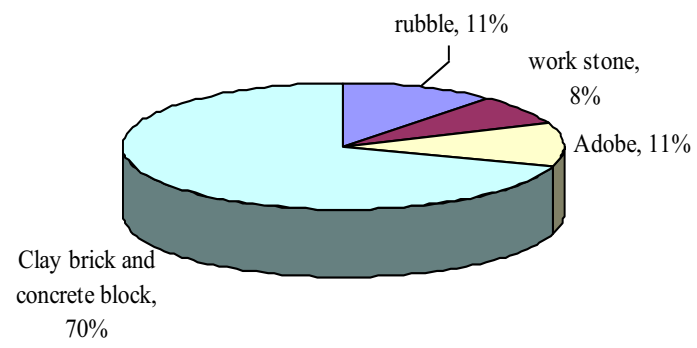

The main wall material

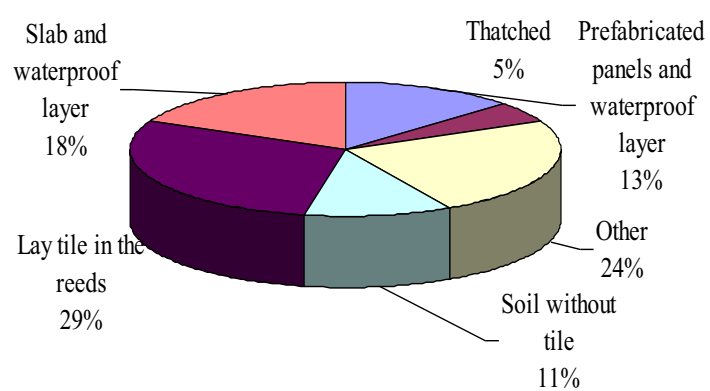

The main form of roof

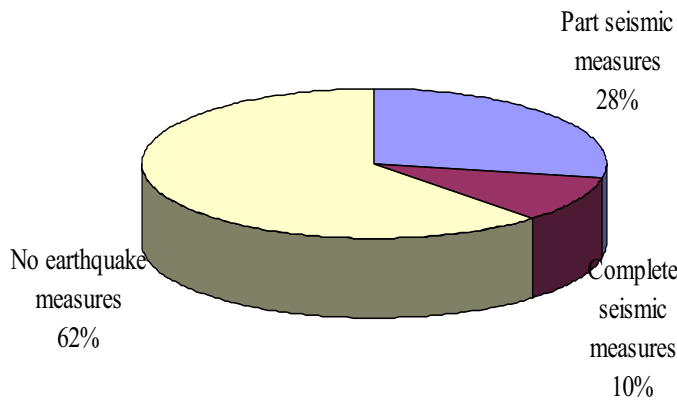

The situation of earthquake structure

Figure 2. Part of survey data of the northern rural areas.

Owing to the fact that northern rural residents lack of experience in terms of earthquake awareness and sophisticated construction technology. Most rural houses' construction quality are poor. And their structure function can not meet the earthquake requirements. Taking into account that the local brick and concrete block are cheap and easy to access. Northern rural housing construction materials are used under the premise of a huge energy consumption. Which can not meet the requirements in saving resources. Moreover, northern rural housing lack of insulation measures. Resulting in a high energy consumption and high heating costs. Due to the lack of appropriate professional guidance and unified settlement planning, residential construction standards in rural areas is uneven, the workers have a poor build technical capacity, and residents are built blindly. Which increasingly unable to meet the needs of new rural construction. Therefore, it is a priority to explore a new materials as a substitute for clay brick for the northern rural areas.

\section{Energy-Saving and Cost Advantages of Straw Bale House}

American architect Jim Hanford has analyzed the energy performance of five kind of walls including adobe houses, fiber concrete, wood frame, foam blocks and straw bale in the US Department of Energy (DOE) laboratory. The ultimate computer analysis showed that straw bale structure can save more than $60 \%$ of energy, which has the best energy-saving effect [4]. Moreover, it is revealed by the contrastive study of thermal engineering and economic behavior between straw bale house and brick 
house that, wall heat consumption is very alarming in an ordinary brick house. At the same time, huge amount of coal consumption in winter increased the burden of atmosphere environmental. Straw bale buildings can relieve the pressure faced by rural ecological environment (Table 1). And it will exploit sustainable local resources effectively. If the combustion of one kilogram of coal will exhaust 1.5 to $2 \mathrm{~kg} \mathrm{CO}^{2}$, about 44.686 more million tons $\mathrm{CO}^{2}$ will be released to air by producing 10 million solid clay brick than the same volume of straw bale. Furthermore, whether manufacturing energy consumption, transport energy consumption or environmental performance, straw bale is better than solid clay brick. According to the statistics, the production of 10 million volumes straw bale will save clay $19,747,800$ tons , land $1750875 \mathrm{~m}^{2}$, coal $167,634,500$ tons, and will reduce the amount of soot emissions from coal-fired 61,312.5 tons. Straw bale house have low heat consumption, high coal saving rate, and short payback period. Those aspects are all better than brick house [5].

Table 1. Comparison of energy consumption for making burned clay brik and straw bale $(\mathrm{kJ} / \mathrm{kg})$

\begin{tabular}{|c|c|c|c|}
\hline \multirow{2}{*}{ Project } & \multicolumn{2}{|c|}{ Clay brick } & \multirow{2}{*}{$\begin{array}{l}\text { Straw bale's } \\
\text { average } \\
\text { value }\end{array}$} \\
\hline & $\begin{array}{l}\text { Average } \\
\text { value }\end{array}$ & Max value & \\
\hline $\begin{array}{c}\text { Production } \\
\text { process-related } \\
\text { heat loss }\end{array}$ & $2615 \sim 2930$ & $3560 \sim 3770$ & \multirow{4}{*}{120} \\
\hline $\begin{array}{c}\text { Energy } \\
\text { consumption } \\
\text { associated } \\
\text { with material } \\
\text { properties } \\
\end{array}$ & $96 \sim 180$ & $340 \sim 500$ & \\
\hline $\begin{array}{l}\text { Basic power } \\
\text { consumption }\end{array}$ & $171 \sim 189$ & $216 \sim 234$ & \\
\hline $\begin{array}{l}\text { Total energy } \\
\text { consumption }\end{array}$ & 2984 3197 & 4134 4486 & \\
\hline
\end{tabular}

\section{The Favorable Conditions to Build Straw Bale House in Northern Rural Areas}

In recent years, the northern rural government regard building ecological civilization village as the strategic emphasis of Balancing Urban and Rural Development and Building Socialist New Countryside. Which aim is improving the rural environment and building a better home. Enclosing the theme of "Constructing Ecological Environment, Developing Ecological Economy, Fostering Ecological Civilization". Working from actual conditions, A group of civilized ecological characteristics villages were constructed based on the mountain specialties, local conditions, overall planning, classified guidance and overall progress. These measures enable the rural landscape has changed dramatically. At the same time,a good ecological, economic and social benefits were created.

\subsection{Climatic conditions advantages}

In recent years, numerous exemplary housing are built combined with active technology and passive technology, like solar thermal storage technology, photovoltaic technology and ground-source heat pump heating technology. Which have received a good social and economic benefits. In this trend, comprehensive design program combing active and passive technology will have a broader applicability.

Most of the northern rural areas have a dry climate, long cold winter and lower temperatures. There are rich of wheat straw resources in northern China's rural areas. So the raw materials of straw bales are easily to access and have a low price. In addition, these local natural resources are renewable, degradable and recyclable, which is the typical properties of green buildings. Moreover, most of the local materials have a simple processing method. And it has a low process energy consumption. The straw bale house have advantages in energy efficient, low cost, good insulation, Etc. Therefore, it has strategic significance for the promotion of straw bale house in underdeveloped mountainous countryside. Furthermore, the straw bale house which has the advantage of eco-efficiency, can provide a practical and effective way for comfort and savings to spend the long winter in mountain areas.

\subsection{Material supply advantages}

Establishment of a modern building system makes concrete, steel and cement spent a lot of land, water, energy and materials. It led to the outstanding problems of air pollution, water pollution, greenhouse effect and solid waste emissions. Which increased a heavy burden of the environment. And it seriously restricts the sustainable development of our country.

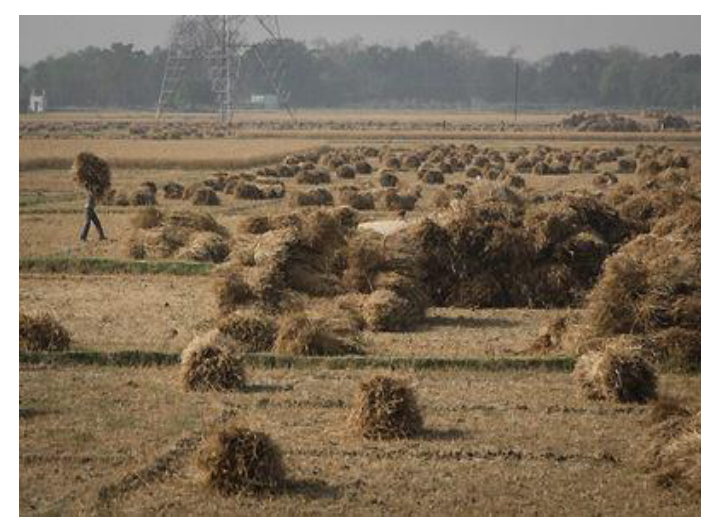

Figure 3. The idle wheat straw in northern rural areas.

Northern rural areas in China are abound of corn and wheat (Fig. 3). And the building can use the local materials without transportation.So, it is enough and convenience for straw bale manufacturing. Moreover, if fully utilized instead of straw burning, air pollution and the greenhouse effect will be less and less. This also reduces the phenomenon that remaining straw occupation of limited land. The most important thing is the accidental or deliberate arson fire can be avoid. Making full use of 
local materials in residential construction in villages, and combined with the ecological construction technology can not only reduce residential energy consumption and environmental stress. It can also reduce the construction costs and improve people' s living comfort. So it has a real significance in the transition of rural residence construction.

\subsection{Cost advantages}

There are a lot of poor people in northern rural areas. At the same time, we are accelerating the pace of new rural construction. And a large number of rural tenements have to be rebuilt. In the past years, crop straw is usually dealt as waste. Which caused waste of resource and the straw' $s$ oversupply. The construction price of straw bale house is lower than ordinary brick house. And its excellent thermal insulation properties can help farmers save a lot of energy consumption costs in their subsequent life. Furthermore, straw bale house have a simple construction technique [6]. Even the people with no construction experience can design and construct it easily. Which will save a lot of labor costs. China's poor population are distributed in the mountainous areas. From the point of farmers' view, economic and practical straw bale house is one of the effective ways to help the poor. In northern rural areas, most of wealthy families build brick houses to symbolize their wealth and success. The aim of lots of hard work for a life time by the farmers is to own a brick house. So they put most of the income into the new house construction. Building costs become their greatest concern. Northern rural residents per capita household income were lower than the national average. To build an inexpensive straw bale house is definitely a good choice for most of the farmers, especially for the elderly people.

\subsection{Straw Bale Houses Should be Vigorously Promoted in the Northern Rural Areas}

Straw bale material makes full use of the renewable plant straw and reduces the pollution of the atmosphere caused by straw burning. Instead of brick, the application of straw bale meet the policy about phasing out of clay. Which can protect arable land and ecological environment and produce a obvious environmental effects [7]. In addition to the widely planting of corn and wheat, straw bale will have a good developing prospect and a strong vitality in northern rural areas.

Nowadays, housing construction in rural northern have two major trends: Firstly, the so-called standards becoming increasingly high. People always pursue luxury exterior and interior. Secondly, due to the lack of architectural concept and scientific technical standards. Rural housing is still stay in the spontaneous construction phase [8]. The comfort, construction function is difficult to improve. Resulting in uncontrolled energy consumption of rural building. As a long time, there are lack of wall materials alternatives to clay brick. Even clay will consume huge amounts of energy, still become the first choice of rural buildings. Thus, considering the global resources and energy shortage, it has a very great practical significance to increase focus on the environmental performance of rural housing. It's imminent to improve the quality of the physical environment of rural housing and reduce energy consumption.

\section{Summary}

Straw bale house is an energy efficient building, who has the benefits of social, economic and environment. And it will has a bright future in the northern rural areas. Straw bale wall has many good performances that many other new environmentally friendly building materials do not. These performances make the straw bale house outstanding in terms of saving energy for heating in winter, saving total investment, ease air pollution and other aspects. The northern rural areas have a sufficient foundations in climate, local materials, and access to energy savings. In the overall context of Accelerating rural ecosystem construction and Promoting vigorously the new socialistic rural building, governments should mobilize the whole society to work together to accelerate the introduction and promotion of straw bale house.

\section{References}

1. $\mathrm{P} . \mathrm{Xu}$, "The Study of Taking Raw Material without Wood Plant Fiber as the Construction Wood-based Panels," New Building Materials, vol. 50, pp. 19-24, Nov. 1996.

2. China Building Energy Saving Annual Development Report, Building Energy Research Center of Tsinghua University, 2014.

3. B. Liu, "The Energy Analysis and Application Prospect of Straw Bale Building in the Northwest Territories," Industrial Construction, vol. 3, pp. 1719 , May 2007.

4. Y. S. Tao, "The energy saving effect analysis of aerated concrete building," New Building Materials, vol. 1, pp. 55-57, July 2005.

5. M. Li, "The Eco-construction Technical Research on Rural Straw Bale House in Yimeng Mountain Areas,' M.E. dissertation, Dept. Elect. Eng., Shandong Agricultural Univ., Taian, China, 2014.

6. X. G. Li, J. Ma, "Research and Application of Straw Bale," Development Guide to Building Materials, vol. 3, pp. 57-60 ,Sep. 2006.

7. L. Ahasteen, D. Bainbridge, L. "Denestone. House of straw. U.S.Department of Energy Efficiency and Renewable Energy," DOE/GO 10094-01, 1995.

8. X. M. Li, Q. D. Li, H. J. Liu, X. D. Xu. "EcoRenovation of the Existing Rural Housing in Yimeng Mountain Area," Applied Mechanics and Materials, vol. 368, pp. 186-189, Nov. 2013. 